\title{
Ethical Principles for Nuclear Power Engineering Decision-Making (A Theoretical Review)
}

\author{
Yao-yao Wei ${ }^{1,2}$, Yu-heng Song ${ }^{1}$ \\ ${ }^{1}$ School of Management, University of South China, Hengyang 421001, China; \\ ${ }^{2}$ School of Marxism, University of South China, Hengyang 421001, China. \\ Email:24359048@qq. com
}

\begin{abstract}
This study examines the Ethical Principles for Nuclear Power Engineering Decision-making (A theoretical Review). The paper investigates the Ethical Principles considered in the decision making process of the nuclear power projects. The three relevant principles discussed are responsibility, justice and ecology. The researches about ethical decision-making of nuclear engineering focus on the aspects including nuclear safety, advantages and disadvantages of nuclear power, and the health and ecological influences of the nuclear engineering. The paper concludes that the implementation of nuclear power projects will have a great impact on social and economic benefits, technological development, human civilization, living standards and ecological environment. Three relevant ethical principles are proposed to help the decision makers of the nuclear projects to improve their decisions in future.
\end{abstract}

Keywords: Nuclear power engineering; decision-making; ethical principle; justice ethics.

\section{Introduction}

As the primary new energy, nuclear power is an inevitable choice for developing market economy, protecting ecological environment and building a harmonious society. However, the lessons of the nuclear accidents, such as Chernotyl and Fukushima, shows that as a double-edged sword, nuclear power and related projects brings great social harm, at the same time benefits mankind ${ }^{[1,2]}$. On the one hand, from the perspectives of economic and technology, nuclear power is a suitable choice for the gradual depletion of resources and an ethical requirement for human development. On the other hand, from the perspective of the safety and ecology, nuclear technology is immoral because it contains anti-ecological and destructive risks. The debate over the implementation of nuclear power projects has never stopped, and this has put the development of nuclear power in a moral dilemma.

The Ethical Decision-making is the specific achievements of the ethical principles of the engineering decisions [2]. It is the summation of morals behavior standards which are used to deal with the dialectical relationships between the decision-making subjects (decision makers) and the decision-making objects (society and environment). The researches about ethical decision-making of nuclear engineering focus on the aspects including "nuclear safety", "advantages and disadvantages of nuclear power" and "the health and ecological influences of the nuclear engineering". The debate about the advantages and disadvantages of the nuclear engineering has never stopped. On the one hand, Max Schulz (2006) proposed the necessity of nuclear power development from the perspective of nuclear power safety and ecological environment [3]. John R. (2005) believes that nuclear power, as clean energy, can effectively curb the greenhouse effect and reduce carbon dioxide emissions from the perspective of energy conservation and emission reduction. And it thus affirms the positive significance of nuclear power project to environmental protection [4]. On the other hand, scholars such as Geoffrey R. Howe (2004) discuss the safety of nuclear power project from nuclear accident and nuclear radiation [5].

In general, the feasibility of project management and technology, the stability of input-output and the economy of decision-making results are the first prerequisite and important support for the project decision processes. However, due to the particularity of social security and ecological risk, nuclear power project should bear the corresponding ethical review and moral evaluation. In this situation, project decision makers should improve their sense of responsibility and make decisions friendly in the environmental and social aspects under the necessary ethical appeals, such as safety, stability and social development, fairness and justice, ecological protection, and so on. After that, an organic integration between the 
decision-making processes and the ethical appeals can be achieved. Therefore, the relevant ethical principles can be discussed in the three aspects of responsibility, justice, ecology.

\section{The Responsibility Principle for Decision-Making Ethics of Nuclear Power Projects}

The coexistence of great interests and risks determines that the decision-making ethics of nuclear power project must be a responsibility ethic ${ }^{[6]}$. Every phase of decision-making of nuclear may have the significant impacts and even some irreversible devastating consequences on the decision objects. Then the moral analysis and evaluation in the view of responsibility is inevitable for decision-making of the nuclear projects. The moral responsibility in project decisions is the behavioral science paradigm means that based on the moral sentiments and moral judgments (such as specific ethical principles and self control), decision subjects (makers) perceive and view the decision processes and results, and then they can take the consequences for their own mistakes ${ }^{[7]}$. Therefore, the main content of the responsibility principle for decision-making ethics of nuclear power projects is how to stimulate, awake and shape the awareness of nuclear security responsibility for ensuring the safe, stable and sustainable development and utility of the nuclear power.

On the one hand, the responsibility principle of nuclear power project is a kind of inter-temporal ethics principles. The traditional ethical views only consider the moral principles of close distance (in the view of time or space) and mainly involve the direct relationship between individuals in the short term ${ }^{[8]}$. In today's globalized and information-based ecological civilization, the boundary of the world system is increasingly blurred. And the relationships between subjects and objects are becoming closer. With the technology carrier, the spread scopes of the triggered events will be enlarged rapidly. In this situation, the traditional ethical principle is unsuitable to adapt to current needs ethical decisions. Therefore, the responsibility ethics principle which keeps up with the times should be based on the long-term and sustainable development of all human beings. And it is a more socialized and collaborative inter-temporal ethics. Under this kind of ethical principle, the decision makers should do as the follows. In the time dimension, not only should we consider the immediate moral values, but also consider the long-term moral values. And it is not only to treat the living as moral objects, but to treat those who are still unborn as moral objects. In the spatial dimension, we should not only have moral responsibility for the people and things around us, but should also determine the moral obligation of decision-making from the perspective of the whole human, the whole biosphere and the ecological environment.

On the other hand, the responsibility principle for nuclear power projects is traceable. The decision-making of nuclear power projects has a great of influence and significance. Irresponsible decision-making behaviors always result in the great "evil consequences" including social and economic losses and human casualties. Although experts have already formed a series of operational standards for nuclear power projects, it is often difficult to enforce the standards because of the opportunism and utilitarianism. Take the Fukushima nuclear accident as a negative example, the refrigeration system failed under the double natural disaster of earthquake and tsunami ${ }^{[9,10]}$. The core melts and the containment vessel ruptured, leading to a nuclear leak and causing a long, serious, irreparable loss. The lessons of history are tragic and priceless. Because human can not predict all the disaster scenarios, and we only can constantly recognize our responsibilities through learning for ensuring the situational adaptability of decision-making. The subjects of nuclear program decision-making, of course, are usually collective rather than individual, which means that the trace processes of responsibility such as monitoring, evaluation and analysis are more complicated. The collective decision-making moral and self-discipline is particularly important. Therefore, for any specific nuclear project decision, it is necessary to carry out detailed and detailed analysis of responsibility from a moral perspective while carrying out post-mortem assessment. Furthermore, we should improve the distribution mechanism of interests and responsibilities, the evaluation and restraint system for responsibility, the responsibility monitoring and tracing mechanism, and cultivate the responsibility consciousness of the decision-making body, thus forming the self-adaptive and traceable responsibility ethical principle. 


\section{The Justice Principle for Decision-Making Ethics of Nuclear Power Projects}

Scholars put forward their views on justice. Macintyre and Urpion believe that justice is the behaviors that give what people deserve without giving what they don't deserve ${ }^{[11]}$. Aristotle and Socrates (1985) consider justice to be the most important wisdom and virtue, morality is justice. Aier, Boersheng and Rawls (2007) believe that it is only fair to uphold human rights under the premise of law. Yang (2000) emphasizes the meaning of equality in justice, and believes that justice means giving and receiving equalization. To sum up the views of scholars, justice is a kind of value judgment, a kind of moral rule and ethical decision-making principle, which both has the connotation of the balance of interest risks and the characteristics of opportunity balance ${ }^{[12]}$. As a measure of the evaluation of decision-making ethics, the unity of subjectivity and objectivity in the process of judgment of project benefit and risk relationship should be guaranteed ${ }^{[13,}$ 14].

Nuclear project decision-making is the game of resource value distribution and risk sharing. Participation and coordination is needed. The relationship between subject and object, as well as the assumption of risk and benefit distribution, should be fully considered. Only when the risk bearers won comparable interests to the harm they suffered and when the interests takers have to bear the project risk and share their interest with the bearers, it would be possible to avoid uneven allocation between stakeholders, making the project effective and realizing the stability and development. Therefore, fairness or justice is another important dimension that must be considered in the decision-making ethics of nuclear project.

The balance between the interests and risks is the key guarantee to realize the justice principle of nuclear power project. Justice is the common desires of all of the human society. Justice of project decisions will directly affect the well-being of people's lives, and it has obvious effect on the promotion of social well-being and the inhibition of social contradictions. In reality, however, nuclear power project in the decision-making process, often by only considering the interests of project decision-making and ignoring the object of feeling, the vulnerable groups to take risks and interests are damaged, so as to stimulate social contradictions, serious consequences. The decision-making risks of nuclear power projects are huge, and the risk interests of the parties involved in various projects are very unbalanced. The nuclear power industry chain is still not fully marketed as a product planned to be traded. This causes the economic value of the nuclear program to be concentrated in one region or a few sectors, while others take risks.

Take the nuclear power industry chain as an example, the undertakers of the nuclear waste reprocessing of spent nuclear fuel bear the huge risk of radiation and nuclear pollution and harm while they may not directly get the benefits from the nuclear power projects; On the contrary, the nuclear power plants gain a lot of interests while they have a relatively low risk of radiation contamination due to the large investment in safety management. What is more, those contamination risk coverage area residents who did not participate in the profit distribution are in the absence of any protection and bear a great of health and environmental risks for free. To some extent, these reflect the lack of justice in the nuclear projects.

Under the justice ethics horizon, nuclear power project decisions should follow the basic principles for the balance between the benefits and risks. It means that when the bearers are bearing risks and suffering damage, some degrees of compensation according to the size of the risk and damage should be provided by those stakeholders who passed the risk of profit to them. Therefore, it is necessary to set up a moral evaluation index system and a system of fair and moral codes for the comprehensive consideration of the common characteristics of nuclear power projects. Taking a specific nuclear power project as an object, it should cover all the subjective and objective factors that influence the decision of the project and should comprehensively consider the reasonable interests, risk allocation or sharing of the different projects participating in the subject and object.

\section{The Ecological Principle for Decision-Making Ethics of Nuclear Power Projects}

"The triumph of new technology in industry is an ecological failure. Each new technology promotes the contradiction between economic interests and ecological environment. The root of this contradiction lies 
not in the realization of technology but in the goal of technology." says Barry Commoner ${ }^{[15]}$. Therefore, if the goal pursued by the development of modern nuclear technology projects is only the production efficiency and surplus value, the lack of attention to the ecological environment needs will lead to a serious ecological crisis. This crisis is not only a part of people or parts of the world, but a global ecological crisis and a moral crisis for all mankind. Human beings must realize that our survival and development depend on the ecological environment. Only by establishing the ethical and moral relationship between man and ecology can we protect the ecological system and natural conditions and maintain the foundation of human development.

The development and utilization of nuclear power projects shows the great power of new nuclear power and may bring more convenience and welfare to human society. Different management methods and technical forms are adopted in the project decision-making, which have different impacts on people's health, daily life and their ecological environment. Once you make a mistake in management or technical decision making, it will have a great impact. We can learn from the nuclear disasters and the unsolved problem of the spent fuel reprocessing that the ecological crisis of nuclear power projects can also bring unpredictable, of irreparable damage to the environment. When such man-made ecological damage exceeds the environmental self-regulation ability, nature will "retaliate" against humanity in its own way. Therefore, the decision of nuclear power project is not only a simple business management behavior or technical operation, but also an important choice to affect the future and fate of mankind and the earth we live in. Whether the decision of nuclear power project is from the perspective of ecology is not only related to the success of the project, but also determines our fate.

The ecological principle of nuclear power project decision-making requires us not only to focus on the economic interests of the project, but also to do the following aspects. First of all, the decision makers should pay attention to "care for nature, great attention to safety, respect for life, environmental protection, energy conservation and emission reduction, collaboration reinforcement", etc., which help the technology utilization of nuclear power project activity to develop in a harmonious, ecological and sustainable way; Secondly, in order to ensure the combination of local and overall interests of the ecological ethics decisions, we should not only consider the interests of the project decision makers in the decision-making processes, but also considered part of interests and the interests of mankind and the ecological environment risk to the global unity of opposites between the three; Finally, in the decision-making of the nuclear projects, decision makers have to consider the factors, such as technical reliability, controllability, safety and environmental impact on the technology of vulnerability, to build a set of high standards for project safety and environmental assessment and to ensure that the project going in order under the ecological ethics and moral principle.

\section{Conclusion}

The implementation of nuclear power projects will have a great impact on social and economic benefits, technological development, human civilization, living standards and ecological environment. Its decision-making process plays a decisive role in the development and utilization of nuclear power technology. To make nuclear power project development becomes better and better, only discussing the economic and technical development is not enough. It is necessary to concise project decision-making and the intrinsic relationships between ethical rules from the perspective of the ethical and moral principles. The paper proposes that besides the technology and economic factors, the ethical perspectives of responsibility, justice, ecology, should also be considered into the decision-making processes of the nuclear engineering projects. And three relevant ethical principles are proposed to help the nuclear project decision makers to improve their decisions in future.

First of all, in the three kinds of ethical principles, responsibility principle is the foundation and core one. Only if the decision-making subjects or stakeholders of the nuclear power projects can be responsible for the decision-making objects including social and environmental, the effective development and reasonable operation project can be prompted and the balance between the interests and risk, safeguard social justice and protect the ecological environment can be ensured. Firstly, the responsibility principle is cross-time, cross-space, systematic, traceable. Establishment of comprehensive, system, discipline, traceable responsibility allocation mechanism, evaluation system and monitor and trace the mechanism are the effective means for achieving power project decision-making in the dimension of ethical views. Secondly, 
justice principle believes that the decision-making of nuclear power project is resource value allocation and risk sharing process of the multi-party game, and the decision makers should obey the basic balance principle between benefits and risks. To achieve justice, a kind of risk evaluation index system and moral justice moral norms system, which are comprehensive consideration of different projects involved in the reasonable interests of the subject and object, risk allocation, should be built. Finally, ecological principle requires policy makers pay more attention to the relationship between economic development and ecological environment. And to realize the harmony of man and nature, it emphasizes to build a high standard of project safety and environmental impact assessment.

Actually, only the questions such as "what kinds of the ethical principles should be obeyed" are the focus of the discussion of this paper. And some other relevant questions such as "What of any violation of ethical principles by Nuclear Power Engineering?" should be discussed in our future works.

\section{Acknowledgement}

Supported by Hunan Provincial Innovation Foundation for Postgraduate (CX2017B506); Hengyang social science fund project (2017D015); Hunan Education Department Excellent Youth Project (No. 17B236); the research is also supported by the Key Discipline of Management Science and Engineering of USC.

\section{References}

1. Showstack R. Fukushima Nuclear Accident Report Calls for More Focus on Threats From Extreme Events[J]. Eos Transactions American Geophysical Union, 2014, 95(31):279-279.

2. Jones. T. M. Ethical Decision Making by Individuals in Organizations: An Issue-Contingent Model [J]. Academy of Management Review. 1991, 16: 366 - 395.

3. Max Schulz. Nuclear Power Is the Future[J].The Wilson Quarterly. 2006, 30(4): 59-63.

4. John R. Coulter. Issues Surrounding Nuclear Power[J].Science, New Series. 2005, 310(28): 619-620

5. Geoffrey R. Howe. Analysis of the Mortality Experience amongst U.S. Nuclear Power Industry Workers after Chronic Low-Dose Exposure to Ionizing Radiation[J]. Radiation Research, 2004, 16(25): 517-526.

6. Stanton N. Human factors in nuclear safety.[J]. Crc Press, 2013.

7. Hayek A Friedrich. Studies in Philosophy, Politics and Economics[M]. New York: Simon and Schuster, 1967:99.

8. Bostrom N, Ord T. The Reversal Test: Eliminating Status Quo Bias in Applied Ethics[J]. Ethics, 2006, 116(4):656-679.

9. Bertsch V, Treitz M, Geldermann J, et al. Sensitivity analyses in multi-attribute decision support for off-site nuclear emergency and recovery management[J]. International Journal of Energy Sector Management, 2007, 1(4):342-365.

10. Tian Xie, Cong-dong Li, Yao-yao Wei, Jian-jun Jiang, Rui Xie. Cross-domain integrating and reasoning spaces for offsite nuclear emergency response[J]. Safety Science. 2016, 85(6):99-116.

11. Linda Klebe Treviño, Gary R. Weaver. Organizational Justice and Ethics Program "Follow-Through": Influences on Employees' Harmful and Helpful Behavior[J]. Business Ethics Quarterly, 2001, 11(4):651-671.

12. Botes A. A comparison between the ethics of justice and the ethics of care. [J]. Journal of Advanced Nursing, 2000 , 32(5):1071-1075.

13. Harvey D. Social Justice and the City[J]. Ethics, 2009, 69(2):180-192.

14. Bero B, Kuhlman A. Teaching ethics to engineers: ethical decision making parallels the engineering design process. [J]. Science \& Engineering Ethics, 2011, 17(3):597-605.

15. Barry Commoner. The Closing Circle[M]. New York: Random House Inc(T), 1971. 